\title{
Vascular anatomy after thrombectomy
}

\section{Mohamed Shehabeldin MD}

\section{CASE 1}

A 78-year-old man with hypertension, diabetes mellitus, and prior tobacco use presented with the acute onset of right hemiparesis and global aphasia with an initial NIHSS of 19. Computed tomography with angiography (CTA) of the head and neck showed

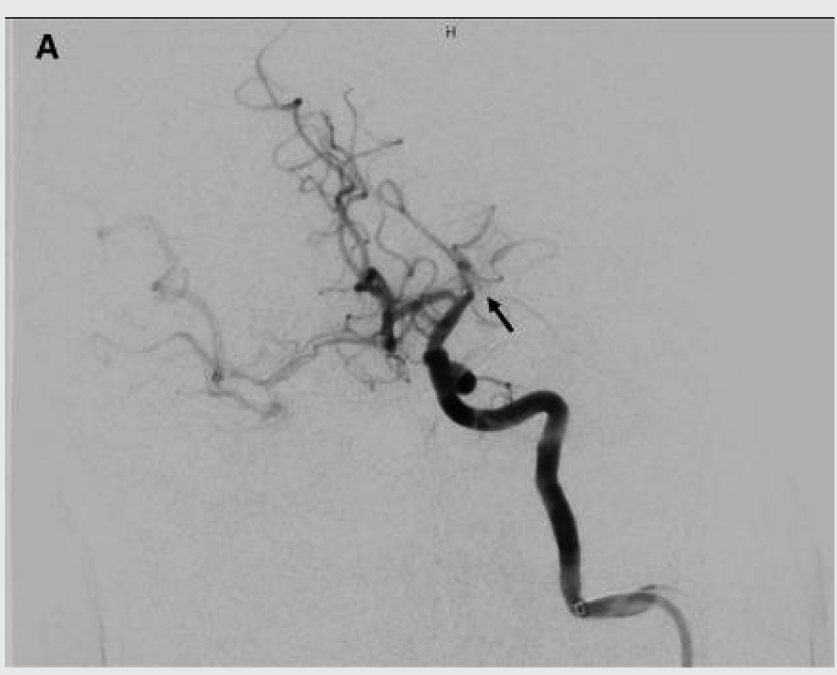

Figure 1A. Posteroanterior view showing complete occlusion of the proximal segment of left MC.

B. Posteroanterior view showing recanalization of the previously occluded left MCA and residual atherosclerotic plaque at the site of the occlusion. occlusion of the proximal segment of the left middle cerebral artery (MCA) (M1 segment). He received intravenous alteplase and underwent mechanical thrombectomy of the left MCA and angioplasty of the proximal MCA segment at the site of occlusion due to residual atherosclerotic stenosis following the thrombectomy.
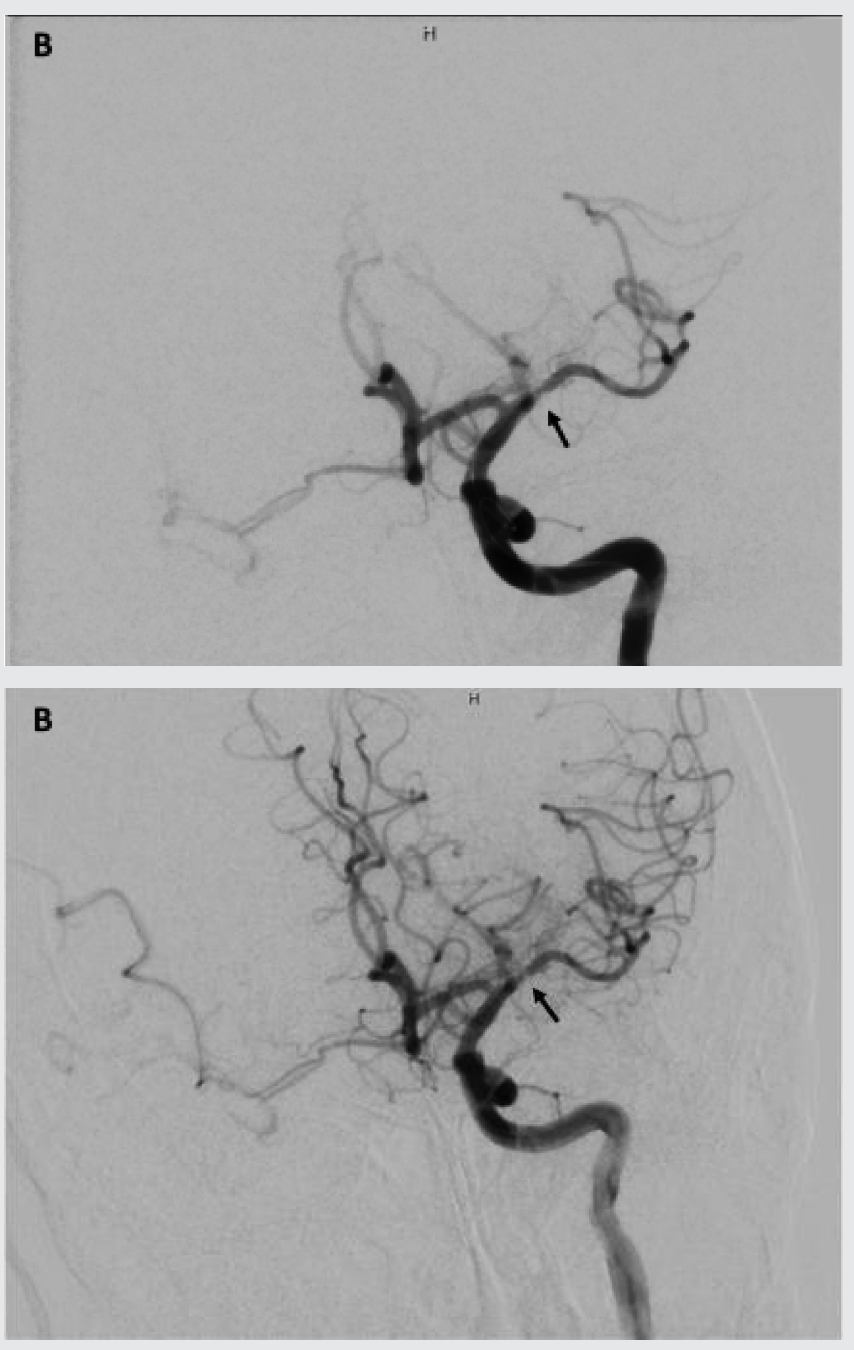

Corresponding author: Mohamed Shehab-Eldin Contact Information: Mohamed.shehab-eldin@ttuhsc.edu DOI: 10.12746/swrccc.v6i26.499 
CASE 2

An 86-year-old man with heart failure, hypertension, Alzheimer's dementia, and atrial fibrillation on anticoagulation which was interrupted for suprapubic catheter placement presented with the acute onset of right hemiplegia, aphasia, and left gaze deviation. His initial NIHSS was 19. A CTA of the head showed left proximal MCA occlusion. Thrombolysis was declined by his family, and he underwent mechanical thrombectomy.
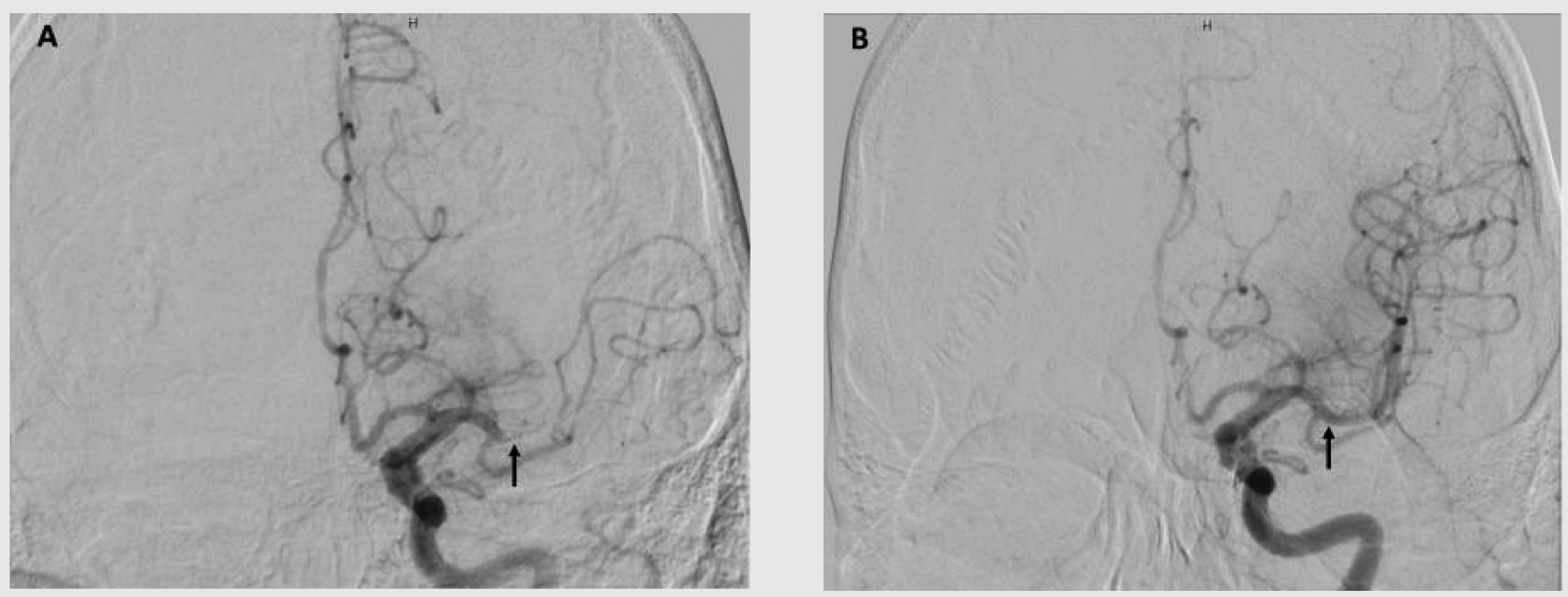

Figure 2A. Posteroanterior view showing complete occlusion of the proximal segment of the left MCA.

B. Posteroanterior view showing recanalization of the proximal segment of the left MCA with normal caliber at the site of the occlusion which suggests a non-atherosclerotic cause of the occlusion.

Keywords: cerebral arteries, stroke, thrombectomy, embolus, atherosclerosis

From: The Department of Neurology at Texas Tech University Health Sciences Center in Lubbock, Texas

Submitted: 10/2/2018

Conflicts of interest: none

This work is licensed under a Creative Commons

Attribution-ShareAlike 4.0 International License 